\title{
The Class of Information Crime and Computer Forensics
}

\author{
Tang Ling \\ Dept. Information Science and Technology \\ East China University of Political Science and Law \\ Shanghai, China \\ E-mail: ausflug163@163.com
}

\begin{abstract}
The world is connected with Internet. However, information crime is threatening the security of Internet.Thus, it is very important for a university to set up a new course to solve the problem and to train the students to deal with information crime and computer forensics. East China University of Political Science and Law has set up a successful class with the name information crime and computer forensics for undergraduate students for nine years and completed some research work. It is the only class which focuses on the problem in China. The students have got many awards. A teaching material is published and honoured by the university and Shanghai education department. Especially, the class has been the important class of Shanghai which is honoured by Shanghai education department.
\end{abstract}

Keywords-computer forensics; information crime; class; education

\section{INTRODUCTION}

Nowadays, we are living in an information era. That is to say, computer technology and Internet service have become one part of outlives. However, information security and crime problems are increasingly serious. For example, in U.S.A, the economic damage caused by hackers' attack is about 10 billion dollar every year. In China, the amount of IP address which is controlled by hackers is about 1 million, and there are 42 thousand websites which are hacked. Every month, 1.8 million computers are infected by computer virus, these accounts for $30 \%$ of the global total.

East China University of Political Science and Law (ECUPL for short) has researched the problem for eight years, and a university course called information crime and computer forensics has been taught for six years. The author joined and accomplished several research projects including national project in succession. The author is the core teacher of the course and is also one of the authors of the teaching material. The author has taught the class for five years, 936 students whom major in computer science, law, business and other departments are included. Based on these education and research experience, the author stared her own postdoctoral work in 2011. And in 2014 the author completed her postdoctoral work.

\section{INFORMATION SECURITY AND COMPUTER FORENSICS}

\section{A. Defination of computer forensics}

Initially, Judd Robbins (senior computer forensic experts) brought out the point that computer forensics is based on the investigation and the analysis techniques which applies to the potential, legal effect evidence. SANS Company believes that computer forensics is the kind of software and tools which according to some pre-defined procedures, comprehensive examination of computers and related systems extract and protect the evidence of computer crime [1].

In China, the computer forensics is defined as: computer forensics refers to the court accepted, sufficiently reliable and persuasive electronic evidence which exists in computers and related peripherals device. Other experts consider that computer forensics is a process can confirm, protect, extract and file electronic evidence which exists in computer and related peripherals, and can make it acceptable and reliable by court. [2]

\section{B. Characters}

Computer forensics technology, compared with the traditional ones, has its own characteristics:

(1) Digital: the material carriers of computer evidence are electronic components, magnetic materials, etc. IF the perpetrator deliberately operates, changes data or programs from the physical representation. The results are only positive and negative electronic integrated circuits or magnetic magnets. To identify this operation, the methods require special tools, and are entirely different from the traditional ones.

(2) Technical: the generation, transmission and storage and collection, analysis and judgments of computer evidence are by means of computer science technology, storage technology and network communication technology.

(3) Vulnerability: As the computer information and electronic evidence can easily be modified and be real changed (irreversible changes) without leaving any traces, so that there is a fragile and unreliable side in computer information. It is very common to know that manipulation of data and the destruction of the program are very universal. And because the computer's processing speed becomes faster and faster, the data changes are instantaneous, the computer evidence is sometimes unreliable [3].

(4) Easily transmitted: With the popularity of Internet technology, a lot of electronic documents such as Email, E-file, etc. can be quickly transferred around the world, which have caused lots of difficulty for the evidence collection either in time or in space.

(5) Human factors: As the computer and network related equipment operation are maintained by operators and system administrators, which need to consider the impact of human factors on the device. The process of computer forensics and equipment should be analyzed in two ways, one is human, and the other is equipment. 


\section{EDUCATION OF INFORMATION SECURITY AND COMPUTER FORENSICS FOR UNIVERSITY STUDENTS}

This part introduces the course itself. The achievement will be brought forth. The reason of its success will be discussed. The future will be designed. And even more, the status of the course all over the word will also be expounded.

\section{A. The status of the course}

This course is a new subject. At first, it was called computer forensics, which was a complementarity to information security specialty. In the recent years, several universities all over the word began to set up special computer forensics subject and some teaching work has started. At the same time, some research institutions also joined in this field. For example, Canterbury Christ Church University sets up the Master Degree of Science in Forensic Computing [4]. It brings together every important aspect of digital forensic examination to support criminal investigation involving digital evidence. The subject areas covered in this outline achieves a balance between the practice and their underpinning theory. As such it is ideally suited for those who are already engaged, or are aiming to develop a career in law enforcement or associated areas both in the UK and elsewhere. In U.S.A., the center of security information system provides some related courses for the Master. California University established the lab for computer security and has begun some technical research.

We can see that these institutions treat the course as a master course or a research point. None of them set up the course in undergraduate education period. This is regret for the college students. And also it is not fit for the situation of information crime.

In China, computer forensics course are only set up for professional police school or set up as a supplement for traditional forensics school. None of the colleges or universities has set up a related course for undergraduate students.

However, in ECUPL, a course called information crime and computer forensics has set up for six years; it is open to the undergraduate students and gets great teaching effect.

\section{B. The course in ECUPL}

ECUPL is a University famous of law school for sixty years. It is one of the first legal universities in China. So undoubtedly, it owns abundant legal background.

The course is setup by the Department of information science and technology, Criminalistics School. The Criminalistics School has stated forensic education and research for more than twenty years. So based on these academic background, we set up the course named information crime and computer forensics as a character subject. It combines computer science and forensics technology even legal knowledge together, and interdisciplinary among each disciplines. We set the course as a professional characteristics class.

In 2005, some research work of information crime and computer forensics has started [5]. The investigation and evaluation of setting a curse has lasted for 2 years. Finally, the Department decided to set up the course.
In 2007, the course was started. Up to now, it is accumulated that eight grades students in the Department with the amount of 380 have been taught. So the author gets a lot of teaching experience. At first, the course is set as a required class for the students of Department of information science and technology. The concrete number of students in every grade is shown in Fig.1.

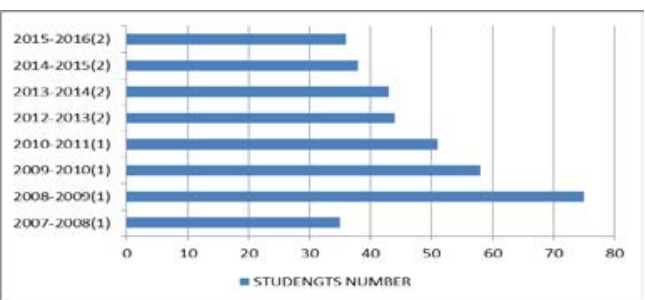

Fig.1. Students number of required class

At the same time, with our investigation, many students in ECUPL are interested in this filed. Thus, in 2009, an elective public class for all of the students in ECUPL was set up. It is set up for eight semesters and 556 students are taught so far. The concrete number of students in every grade is shown in Fig.2.

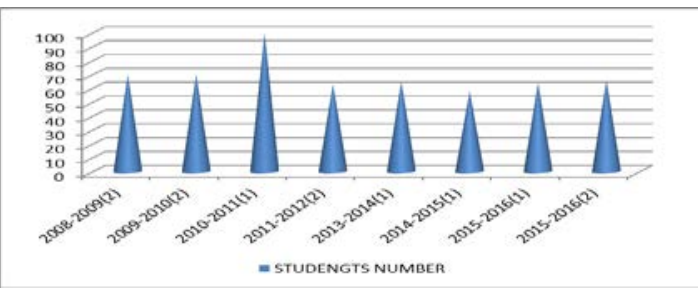

Fig.2. Students number of elective public class

It should be noted that the required class and the elective class are different and have their own characters. The former is a professional class, and the students are major in computer science. So it is difficulty of profession and requires seven experiments. The latter is for all of the students in the university. Most of them come from legal school, business school, even from sociology school. So considering their background and their intension are for broadening their knowledge, the difficulty of the class is reduced, the interest of the class is enhanced. Some information security knowledge even some skills to prevent their computers form hackers are taught in class. As to the professional experiments, they are demonstrated by teacher instead of practicing by students.

In 2013 the class has been the important class in Shanghai honored by Shanghai education department.

\section{THE COURSE IN DETAILS}

In this section, the details of the course will be introduced. And the achievement of the students will also been shown. The teaching material will be discussed.

\section{A. The required course in detail}

At first, the course was 3 credits, that is to say, there were three continuous classes ever week, including experiment class. But after a period of teaching, we found that this is not fit for the need of teaching. So we adjusted the teaching plan. First, 
the course is changed into 4 credits, which means 4 classes are taught every week. The 4 classes are divided into 2 parts. The course is taught for 2 times every week, each time there are only 2 continuous classes. And considering the difficulty of the course, there is at least one -day interval between 2 times of teaching. For example, 2 classes are set on Tuesday, the other are set on Thursday. So on Wednesday, the students can have sufficient time to review and preview the course. According to effect of the students, this adjustment achieves great results.

This course requires not only theoretical exploration but also practice capacity. So the teacher attaches great importance to the experiment. There are seven experiments in this class, including the recovery of hard disk, the encryption and decryption of electronic data, the forensics of computer log system, and sniffer on Internet. The department invested 2million RMB to build a professional internet and information lab. And bought some software, hardware and supporting equipment .Now it can support about 50 students to practice at the same time. In order to improve the effect of experiments, the lab is divided into 8 groups; each one is settled by a hexagonal lab table and can form a subnet. Every group is connected by network with each other. The teacher's computer is set as server to connect with Internet. The students in each group can cooperate with each other to complete the experiment. And the teacher also can arrange a simulated computer attack and defense scene. Some groups act as the roles of hackers. Some act as the roles of computer forensics experts. So they can interact with each other and the interest of the class is improved [6].

These experiments not only consolidate the theoretical knowledge, but also improve their practice capacity. It is because of our attention to the experiments; our students can not only get excellent ranking in related competition, but also be popular with employers. At the end of each experiment, the students should finish their experimental reports. In order to be strict with quality of the class, the teacher always checks their results by random .Their score will be part of their final grade.

\section{B. The elective class in detail}

As mentioned above, there is an elective class with the same name but different class ID and difficulty in the university. It is open to all of the students in the university and is set for 2 classes every week. Considering the conflict with their professional classes, the course is arranged in the evening. And due to their knowledge of computer science is not professional, the difficulty is decreased. The assessment method of the class is more flexible, most of the time; the exam is the demand of an article. As to the experiments, owing to their lack of computer science knowledge, the teacher demonstrates the experiments in lab instead of the traditional experiment manners. In this way, not only has the burden of the students been lightened, but also can learn through practice.

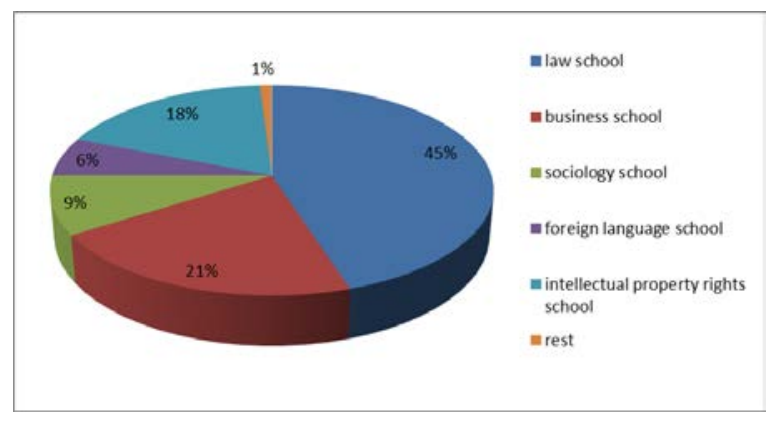

Fig.3. the source of students from different schools

According to the statistics shown in firure3, the source of students comes from more than five schools. Most of the students (45\%) come from law school. It validates the character of the course: combining computer science with forensics and law issues. $21 \%$ of the students are from business school. With the development of electronic business, more and more business disputes or crimes involve electronic data, such as electronic signature, electronic accounting. This leads to the concern of computer forensics. It is a new challenge and requirement for forensic accounting. Nowadays, more and more experts have realized this problem. For example, in 2010, China University of Political Science and Law began to recruit he students major in electronic forensic accounting for Master Degree[7]. In the ECUPL, some graduate students in business school also do some research in electronic forensic accounting. But as above-mentioned in this paper, due to the students are lack of information crime and computer forensics education background in undergraduate period, they have difficulty in understanding this concept. So the elective course is a good introduction or complementarity for them. Thus, this explains the percent of business school in this course.18\% of the students are from intellectual property rights school. At present, with the popularity of computers and the Internet, many works, audio and video products are made from electronic form. So their copyrights are easily pirated and are difficult to be tracked. This situation results in the focus of computer forensics whether in cases or in research. Other students are from foreign language school, sociology school, etc.

In conclusion, by the use of scientific teaching methods, the author succeeds in teaching the course as a required one and an elective one against different students.

\section{The teaching material}

At first, we used a teaching material named Internet crime and computer forensics. But as time went on, we found that it was not fit for the class. For example, crime on Internet is only a part of information crime. There are other forms of crime, such as mobile crime, PDA crime, etc. With our research of the teaching material market, we drew the conclusion that none of the books meet our need. And Based on our teaching experience, in2009, our department and Dr. Qi Man in Canterbury Christ church university decided to wrote a teaching material by ourselves. The book is named as <information crime and computer forensics>, published by Beijing University publishing house. The author wrote chapter five: the discovery and collecting of electronic evidence. The chapter is about 50,000 words. In September, 2010, the book is 
put into practice. Up to now, students from 4 grades have used them, and get satisfactory results. In2011, the book is horned as the second prize of excellent teaching material of university in Shanghai 2011.

In 2016, we decide to publish the second edition of the book and what's more a new book named as the supporting experiments material is planned. This work can improve the construction of teaching material and the quality of the class.

\section{The achievement of the students}

After class, the author organize several research teams voluntarily, they can discover the field of information crime and computer forensics by interest. Two of them are very excellent, and get the support of the university fund for students.

In 2008, the author led two teams of students to join in the 1st information security competition of all universities in Shanghai. One team is honored as the runner-up; the other team is honored as the prize for excellence. It should be noted that the runner-up won the championship in the experiment section and over time section, only flailed in the test paper section. It was a satisfying record. In 2015, the author led three students and joined the 1st computer forensics competition of all China Political Science Universities and Police Universities, and won the third prize of person and team. In 2016, the students also joined some competitions and got great achievements.

As to the students study perspective, there are dozens of students study Master degree in succession. Some of them choose to major in computer science, some of them major in computer forensics, another major in law.

\section{RESEARCH WORK}

As a teacher in university, research is also an important work. It is well known that through research, the teacher can improve their professional quality, widen their knowledge. And put the research results into teaching, to further improve the quality of teaching.

In the class, the author usually combines the latest research result of this discipline with the knowledge in book flexibly. If time permits, the author set up a unique lecture to introduce the research situation and to inspire the students in academic way.

In 2016, the author completed three research projects as the leader. One is a project to discover the computer forensics problems which lasted for 3 years. The other one is a teaching reform project focus on information crime and computer forensics, which lasted for 2 years. The last one is supported by China Law Society, the research finding is published. Now, the author has been the member of two projects. One is National
Social Science Foundation of China; the other is National Important Social Science Foundation of China

Some projects are in process. There are three projects. One is a national project focus on electronic evidence; the author is responsible for the part of computer forensics. The other is a project called major constriction class in university, the author is the principal and decide to complete the project in 3 three years. The rest one is a Science Foundation of ECUPL focus on law issue in computer forensics, the author is also the principal of the project.

\section{THE FUTURE WORK IN BIG DATA}

With the development of computer technology, new information crime comes out endlessly. Today, Internet has entered the big data era .So the computer forensics will face new problems and keep on developing new technology. The author needs improve the teaching work, surmise and optimize the experience of teaching. In the future, the author will enlarge the current teaching achievement and improve the quality of class. This will benefit the students undoubtedly.

\section{CONCLUSION}

In this article, the author introduces the current situation of information crime and computer forensics and the production of the class.

On the basis of this, the author summarizes the development and thinks about the trend of the discipline.

Information crime and computer forensics is a cross subject. It combines computer science with forensics and law. Although it is a young subject, it is a super excellence way to resolve the increasingly serious information crime situation. Thus, the subject will develop very soon. The author thinks that new research work will come out in the big data era.

\section{REFERENCES}

[1] Robbins, Judd. "An Explanation of Computer Forensics." URL: http://www.computerforensics.net/forensics.htm.

[2] Chen Long, Mai Yong Hao, Huang Chuan He , The Technology of Computer Forensics, Wuhan University Publishing house,2007, pp.1-10.

[3] Peter Sommer: “Computer Forensics: an Introduction”URL: http://www.virtualcity.co.uk/vcaforens.htm

[4] URL: http://www.canterbury.ac.uk/studyhere/HomeNew.aspx

[5] Dang En Hong, the Analssis of computer forensics. China Water Transport.vol08,2007

[6] Song XiuLi, Chen Long, Deng HongYao.The discovery of computer foensics experiments teahing, vol26(16, 2007)

[7] URL:http://gate.cupl.edu.cn/yjs 